\title{
Mechanical characterisation of lacustrine clay by interpreting spatial variability in CPTU measurements
}

\author{
Giovanna Vessia \\ Canales y Puertos (UCLM), Ciudad Real, Spain \\ Francesca Casini \& Sarah Springman \\ Institute for Geotechnical Engineering, ETH, Zurich, Switzerland
}

\begin{abstract}
Transportation infrastructure is common in highly populated areas near the major lakes in the Swiss 'Mittelland', where extensive deposits of normally consolidated post glacial clays have formed. Construction on, or in, such soils requires careful consideration during the design process due to their compressibility, low permeability and sensitivity. Achieving a satisfactory engineering characterisation requires a range of field and laboratory tests, which may be evaluated using statistical tools. The Intraclass ratio RI and the modified Bartlett method have been employed for interpreting the variability of the undrained shear strength $s_{u}$ from continuous CPTU measurements at the Wauwil site. Finally, comparison between measurements from two cone dimensions, of cross sectional areas of $10 \mathrm{~cm}^{2}$ and $5 \mathrm{~cm}^{2}$, has been undertaken with respect to their capacity of profile detailing based on the normalised cone penetration resistance $\mathrm{Q}_{\mathrm{t}}$.
\end{abstract}

\section{INTRODUCTION}

The deposits of lacustrine clays in Switzerland are mainly concentrated in the Mittelland (Fig. 1), which is located between the Alps and the Jura mountains. This region is the most densely populated and fastest developing area in terms of infrastructure and construction, so the lacustrine clay represents one of the most challenging soils with respect to foundations and construction (Messerklinger 2006).

Lacustrine clay or varved clay is defined as alternating thin layers of silt or fine sand and clay, formed by variations in sedimentation rate during the various seasons of the year. Often these layers will exhibit contrasting colours when partially dried.

The formation of local lacustrine clay deposits in Switzerland, and their basic properties, are described in detail by e.g. Rey (1994). The response of lacustrine and varved clays was studied by different authors (e.g. Heil et al.1997; De Groot \& Lutenegger 2003; Soccodato 2003; Trausch Giudici 2004; Messerklinger 2006). The prominent features in such soils are the time dependent and high compressibility of the clay layers, and the anisotropy of the silty layers, which play an important role when estimating time for any excess pore pressure dissipation following construction in the field. The horizontal layering induces a difference in the

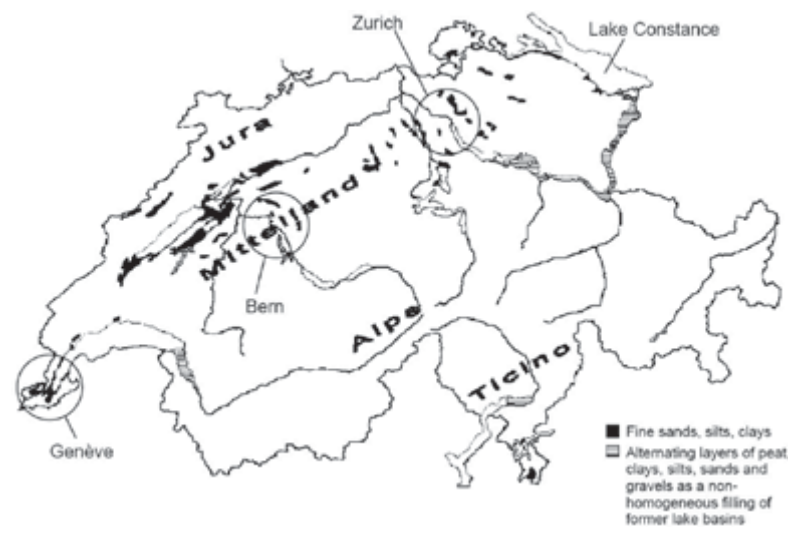

Figure 1. Swiss lacustrine clay distribution (source: Hydrogeological map of Switzerland, after Trausch Giudici 2004).

anisotropy of the permeability parameter causing a considerably faster consolidation rate (Trausch Giudici 2004) than predicted by one-dimensional consolidation theory.

Accordingly, Swiss practice is focusing more on serviceability limit state design for infrastructure (e.g. roads, retaining walls), with the intent to achieve optimal (i.e., more economic) design. The optimisation of design between client, engineer and contractor through value engineering, may well become of increasing interest (Springman et al., 1999). 
To this end, cone penetration tests (CPTU) have been widely performed within lacustrine clays in Switzerland in order to get detailed information about the stratigraphy, mechanical and hydraulic properties. Nonetheless, measurements from CPTU continuous readings are strongly affected by inherent spatial variability and heterogeneity.

Thus statistical tools can be usefully introduced to improve the soil characterization, to establish characteristic values for key parameters for optimal design of geo-structures in such varved clays.

\section{MECHANICAL CHARACTERISATION OF CLAYS BY CPTU INTERPRETATION}

CPTUs have been adopted in such glacial clays in recent years, in order to design transportation infrastructure in Switzerland (Heil et al. 1997; Springman et al. 1999). Recently, Hird \& Springman (2006) investigated the feasibility of detecting silt layers as thin as $\sim 5 \mathrm{~mm}$ by comparing pore pressure profiles from CPTUs using piezocones with $5 \mathrm{~cm}^{2}$ and $10 \mathrm{~cm}^{2}$ cross sectional areas, which were performed at the Wauwil site (Fig. 1). The $5 \mathrm{~cm}^{2}$ piezocone appeared to be able to achieve a more accurate prediction of the location and extent of the silt/clay layers, although variability in cone resistance $\left(\mathrm{q}_{\mathrm{c}}\right)$ and pore pressure $\left(\mathrm{u}_{2}\right)$ profiles affects the precision mostly where silty and sandy lenses or inclusions are crossed. Furthermore, Springman et al. (1999) tried to derive appropriate properties for designing structures in Kreuzlingen clay by comparing field and laboratory tests. They derived $s_{u}$ values from cone tip resistance $q_{c}$ and pore pressure $\mathrm{u}_{2}$ by means of the standard equations:

$s_{u}=\frac{q_{t, n e t}}{N_{k t}}$

where $\mathrm{N}_{\mathrm{kt}}$ is the cone factor and $\mathrm{q}_{\mathrm{t}, \text { net }}$ is the total pressure acting on the cone tip:

$q_{t, \text { net }}=q_{c}-u_{2}(1-a)$

where a is the net area ratio, being 0.76 for the $10 \mathrm{~cm}^{2}$ and 0.6 for the $5 \mathrm{~cm}^{2}$ piezocone.

$\mathrm{N}_{\mathrm{kt}}$ values depend on the roughness of the cone and also on the stiffness index of soil (shear stiffness normalized by $s_{u}$ ) (Hai-Sui Yu 2004). It was found to vary from 10 to 17.5 , for rough cones. Heil et al. (1997) correlated field vane and borehole vane test data with cone data for Kreuzlingen clay to give a $\mathrm{N}_{\mathrm{kt}}$ equal to 17 . It is higher than might be expected on the basis on previously suggested range of values, although a sensitivity of 3 to 5 may be partially responsible. Springman et al. (1999) suggested a linear trend for a characteristic undrained shear strength $s_{u}$ for Kreuzlingen clay that was supported by triaxial stress path data as well in compression and extension (see Fig. 2).

Such an expression takes the minimum $\mathrm{s}_{\mathrm{u}}$ measured values into account because it cannot interpret the variability of $\mathrm{q}_{\mathrm{c}}$ and $\mathrm{u}_{2}$ readings (Fig. 2). Comparison between $s_{u}$ data from vane tests and CPTU devices did not enable deterministic inspection reducing the variability in $s_{u}$ trend shown by field and laboratory tests (Fig. 2) at the Kreuzlingen site.

An extensive site and laboratory investigations were carried out on a small area in Wauwil in a thick deposit of Swiss lacustrine clay about $70 \mathrm{~km}$ SW of Zurich (Fig. 3).

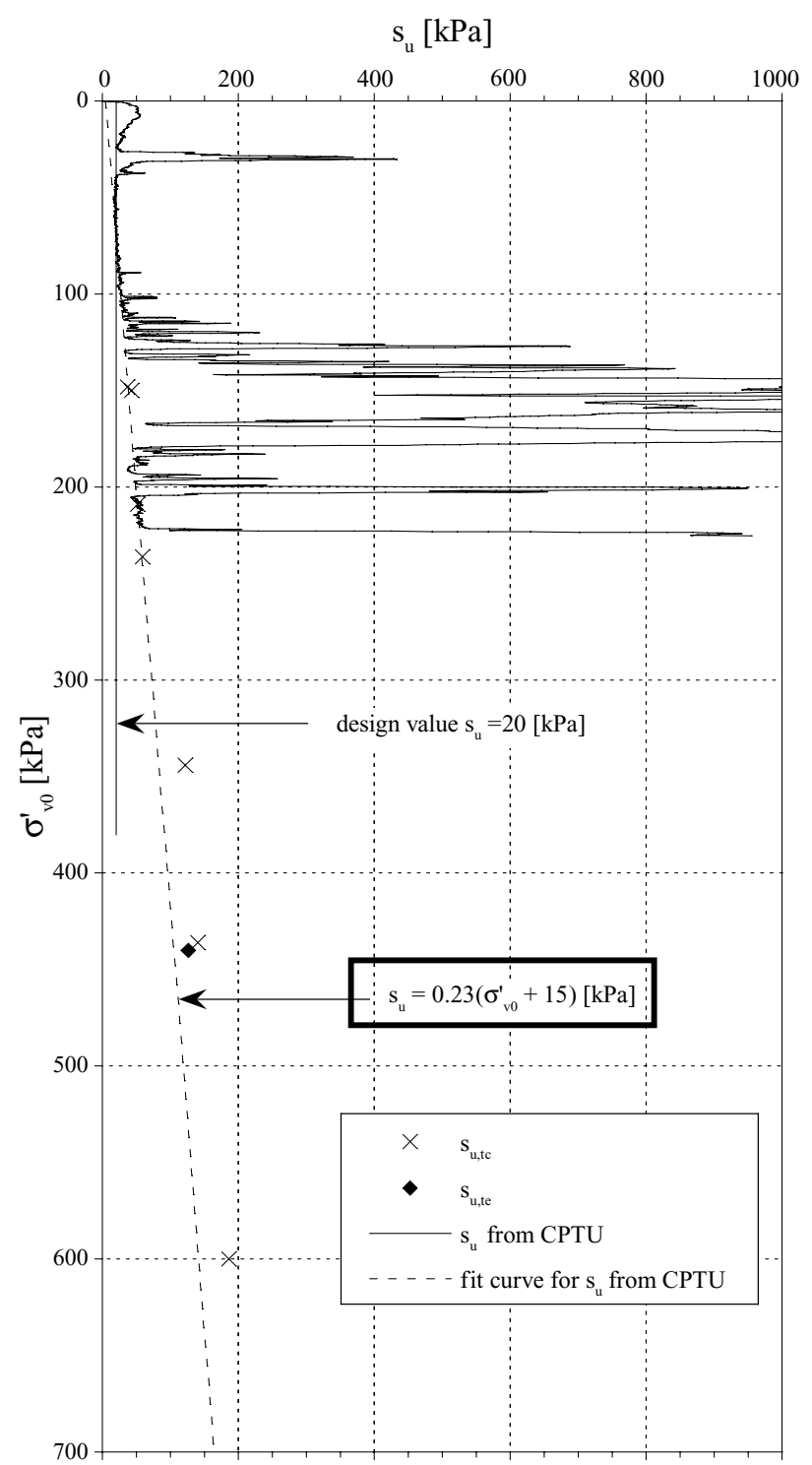

Figure 2. Correlation for undrained shear strength drawn from different tests performed at Kreuzlingen (after Springman et al., 1999). 


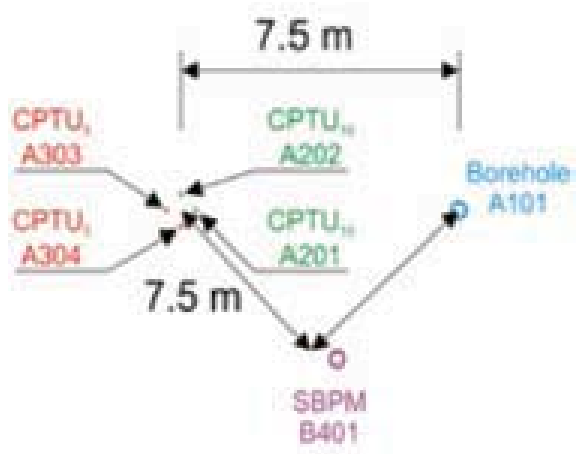

Figure 3. Plan on site investigations at Wauwil site.

\section{Soil description}

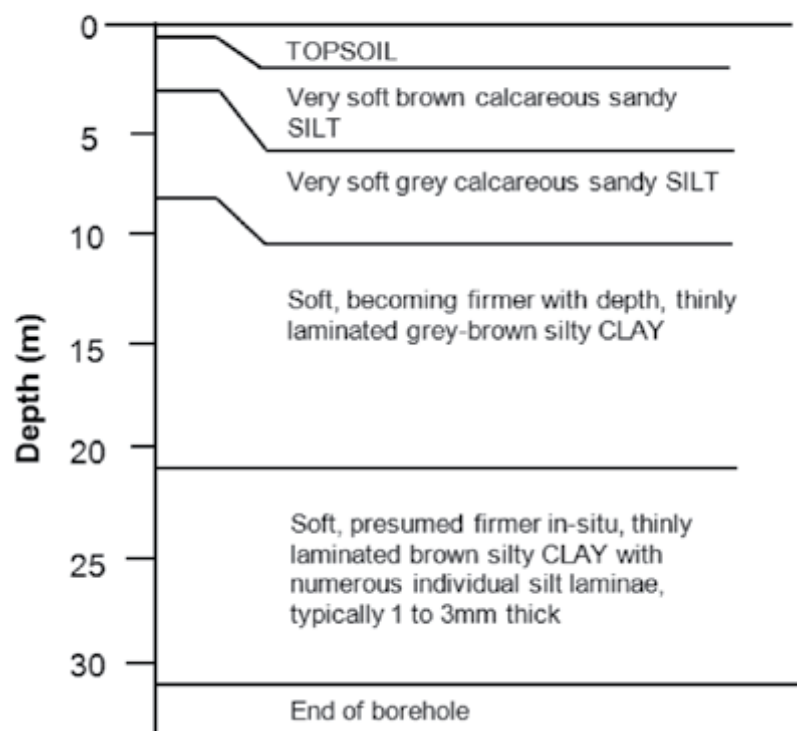

Figure 4. Geotechnical profile from CPTUs and boreholes at Wauwil (after Hird \& Springman, 2006).

The ground profile (Fig. 4) has been derived by comparing data from boreholes, in situ geotechnical tests and mineralogical investigations. However, no criteria have been applied for making a detailed profile, where both layer boundaries and lenses at a scale of a centimetre width can be recognised. Accordingly, CPTU readings performed at the Wauwil site have been re-analysed by means of statistical tools.

\section{STATISTICAL TOOLS FOR LAYERING DETECTION FROM $\mathrm{Q}_{\mathrm{T}}$ READINGS}

Several authors (e.g. Uzielli et al. 2005, Phoon et al. 2003, Cherubini et al. 2007, Uzielli \& Mayne 2008) interpreted the variability shown by CPT and CPTU readings by means of the theory of random fields (Vanmarcke 1983), with good results. Continuous measurements from piezocone tests are the most useful readings for dealing with spatial variability from a statistical standpoint, although such variability commonly can be attributed to different sources. Disregarding the possibility of human errors in performing the tests, the variability in cone tip resistance $q_{t}$, friction resistance $f_{r}$ and pore pressure $u_{2}$ can be attributed to three causes: (1) the presence of layers, which is referred to as soil heterogeneity; (2) the presence of local lenses, inclusions or other anomalous elements interbedded into layers, which can locally influence the mean trend of CPT or CPTU readings, without affecting a more global characterisation; (3) the inherent variability of soil properties within homogeneous soil layers, which is due to the spatial correlation of soil properties at different lengths over the fluctuation scale.

The preceding points (1) and (2) are generally considered as one for statistical profiling task because commonly the spatial lag between adjacent measures are that high-greater than $10 \mathrm{~cm}$ order of magnitude - so that only layer boundaries can be distinguished and identified.

The CPTUs at the Wauwil site have been performed with two cone dimensions: cross-sectional areas of $10 \mathrm{~cm}^{2}$ and $5 \mathrm{~cm}^{2}$; the data were saved at the rate of 25 readings per second and the standard rate of penetration was $20 \mathrm{~mm} / \mathrm{s}$. Therefore, spatial lags of measurements are about $0.5 \mathrm{~mm}$ on average. Thus statistical methods have been employed to develop a more precise prediction of both anomalies and layer boundaries at a centimetre scale. Moreover, a comparison between statistical information, derived from $10 \mathrm{~cm}^{2}$ and $5 \mathrm{~cm}^{2}$ CPTUs, has been presented.

The study undertaken hereinafter aims at achieving the following objectives:

1. to develop a statistical procedure for detecting layer boundaries and determine the depth of anomalies, which can be attributed to lenses or local heterogeneities;

2. to calculate a representative mean trend, standard deviation and the scale of fluctuation for lacustrine clay from the Wauwil site;

3. to investigate the differences between $10 \mathrm{~cm}^{2}$ and $5 \mathrm{~cm}^{2}$ piezocone data, which can be exploited for statistical analyses.

Normalised cone resistance $\mathrm{Q}_{\mathrm{t}}$, that is:

$Q_{t}=\frac{q_{T, n e t}}{\sigma_{v 0}^{\prime}}$

has been considered as the primary parameter because it reflects mobilisation of a spherical volume ahead of the penetrometer and can be used in all stages of soil characterisation, from lithological to mechanical. 
Moreover $\mathrm{Q}_{t}$ random variable profiles represent the variability in $\mathrm{q}_{\mathrm{t}, \text { net }}$ and $\mathrm{s}_{\mathrm{u}}$ with respect to a statistical point of view, because all of them are multiplied or divided by constant values, or linear functions, which do not have random properties. Mean trend, variance and fluctuation scale can be derived from $Q_{t}$ data for each layer, which can be easily related to $\mathrm{q}_{\mathrm{t}, \mathrm{net}}$ and $\mathrm{s}_{\mathrm{u}}$ by scaling their mean trends by the appropriate quantities. The variance and the fluctuation scale are not affected by such scaling factors because they relate to residuals.

The authors focused on the CPTUs reported in Fig. 3 namely: A201, A202, A303, A304. Their $Q_{t}$ profiles are presented in Figure 5.

\subsection{Soil parameter spatial variability according to random field theory}

Soil properties, which are measured in field, can be considered as a spatial random variable with a structure of a trend and a fluctuating component. The fluctuations of soil measurements about a mean trend function can be represented by means of the following expression:

$$
x(z)=g(z)-t(z)
$$

where $\mathrm{x}(\mathrm{z})$ is the fluctuating component, $\mathrm{t}(\mathrm{z})$ is the trend function and $g(z)$ is the measurement of the soil parameter at each depth. Whenever the fluctuations are stationary, even in a weak sense, the random variable can be fully described by the standard deviation and the autocovariance function $\mathrm{R}(\tau)$

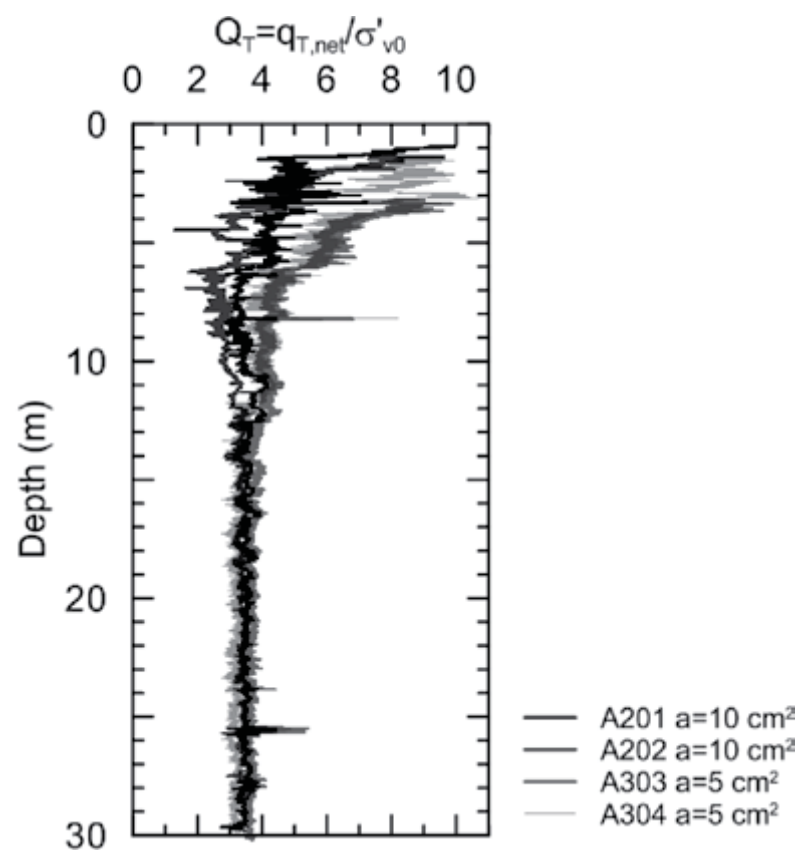

Figure 5. $\mathrm{Q}_{\mathrm{t}}$ profiles from Wauwil site. according to one-dimensional random field theory. Such a function is commonly normalised by the measurement variance to form the autocorrelation function, which can be estimated using the method of moments, as follows (Fenton 1999):

$R(\tau=j \Delta z) \approx \frac{1}{s^{2}(n-j-1)} \sum_{i=1}^{n-j}\left[x\left(z_{i}\right) x\left(z_{i+j}\right)\right]$

where $\Delta z$ is the sampling interval; $z_{i}$ is the depth coordinate of $i$ th sampling point, $\mathrm{n}$ is the number of data points, $s^{2}$ is the sample variance.

Accordingly, in order to derive the spatial random structure of the soil parameter, it is necessary to undertake the following steps:

1. to recognise homogeneous soil layers;

2. to de-trend the measurement profiles in order to determine residuals by Eq. (4);

3 . to verify the weak stationarity of residuals and calculate their standard deviation;

4. to calculate the autocorrelation function (Eq. (5)) and to fit it by means of autocorrelation models;

5 to derive the fluctuation scale from the best fitting autocorrelation model.

Such tasks can be accomplished by means of different methods. The authors present a combination of the intraclass correlation coefficient RI (Wickremesinge \& Campanella 1991), the modified Bartlett method (Phoon et al. 2003) and the moment method (Fenton 1999).

\subsubsection{Intraclass correlation coefficient RI for layer boundary detection}

The intraclass index method (Wickremesinghe \& Campanella 1991) has been applied to the readings shown in Figure 5 in order to recognise homogeneous soil layers. This method consists of moving two contiguous windows containing $\mathrm{m}$ data points over a measurement profile and comparing the variance of each of the two windows, with the pooled variance of the preceding two windows ( $2 \mathrm{~m}$ dimension), by means of the intraclass correlation coefficient $\mathrm{RI}$ :

$R I=\frac{s_{b}^{2}}{s_{b}^{2}+s_{p}^{2}}$

where $\mathrm{s}_{\mathrm{b}}^{2}$ is the variance of the combined samples of size $2 \mathrm{~m}$ and $\mathrm{s}_{\mathrm{p}}{ }^{2}$ is the pooled combined variance calculated as:

$s_{p}^{2}=\frac{n \cdot\left(s_{1}^{2}+s_{2}^{2}\right)}{2 n-1}$ 
where $s_{1}^{2}$ and $s_{2}^{2}$ are the variances of the contiguous sample windows with $\mathrm{m}$ data. Finally, a profile of RI is built; RI values are set at the centre of two contiguous windows. From a statistical standpoint, the RI profile will attain a peak every time the optimal layer boundary depth is crossed. Based on expertise developed by the applications of such procedure, a peak value of 0.8 indicates the presence of a layer boundary/lens at the centre of the window. Further details on RI applications can be found in Wickremesinghe \& Campanella (1991) and Cherubini \& Vessia (2006), whereas this study focuses on two aspects of this powerful tool for layer detection:

1. to establish the criterion by which lenses can be distinguished from boundary interfaces;

2. to highlight the role of cone dimension on RI peaks over the depth.

The optimal dimension of the windows has been assessed for the first goal, in order to achieve high precision, as well as to show RI peaks. Thus, nine RI profiles have been considered for windows from 3 to $10 \mathrm{~mm}$ in length. The window lengths at which RI reaches its maximum values have been used for the layer boundary detection and were found to be 7, 8 and $9 \mathrm{~mm}$. Figures $6 \mathrm{a}$ )-d) show RI profiles from 0.8 to $30 \mathrm{~m}$ depth for the four CPTUs: they are all used to identify the depths at which RI peaks were detected. Moreover, the comparison of all the RI profiles suggests clearly how to distinguish the layer boundary from a simple inclusion.

As the dark circles show, where the peaks are numerous and are registered for a depth of more than $1 \mathrm{~m}$, it can be considered that a layer boundary has been identified; whereas depths at which numerous peaks from different windows are concentrated over the centimetre scale will imply the existence of lenses, whereby the lenses will not be considered in the random structure. Accordingly, four layer boundaries (continuous circles) and three lenses (dotted circles) have been detected in Figures 6a)-d). Such profiling is gained from windows of 14,16 and $18 \mathrm{~mm}$ lengths, so that the error of such an estimation is $9 \mathrm{~mm}$ at most above and below the real boundary. This precision is quite high and allowed the authors to detect three lenses, each of $20 \mathrm{~cm}$ depth.

Thus, according to the statistical profiling five layers can be recognized, up to: $3.4 \mathrm{~m}, 15.5 \mathrm{~m}$, $24.4 \mathrm{~m}, 28 \mathrm{~m}$ and $31 \mathrm{~m}$ depth; whereas three main lenses, among local anomalous values, can be detected at $8.2 \mathrm{~m}, 18.7 \mathrm{~m}$ and $29.5 \mathrm{~m}$ depths. These are the results obtained from all of the RI profiles, from both $5 \mathrm{~cm}^{2}$ and $10 \mathrm{~cm}^{2}$ cone dimensions.

Analysing the RI profiles separately reveals similarities and differences. Considering Figures 7 a)-d) for the $10 \mathrm{~cm}^{2}$ cone (A201) and for the $5 \mathrm{~cm}^{2}$
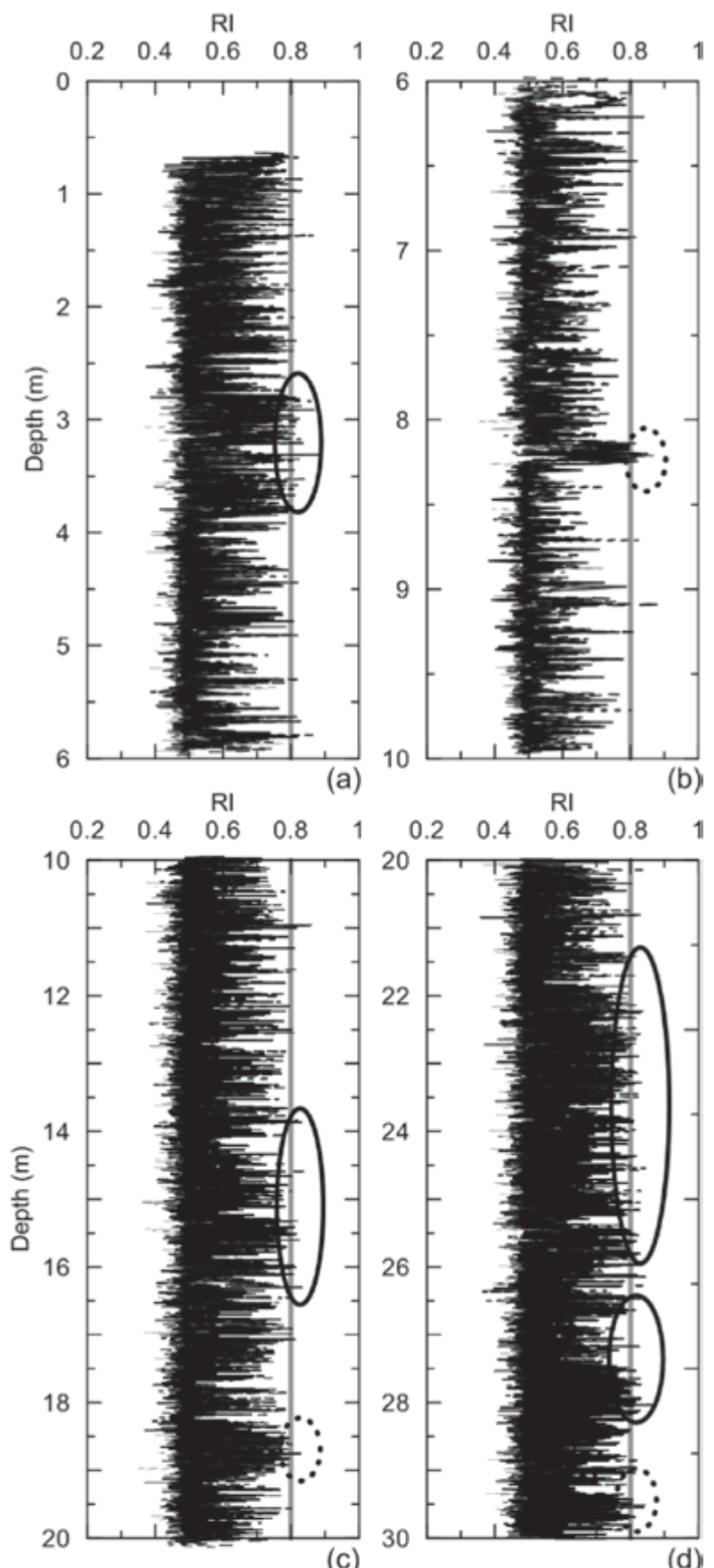

(c)

(d)

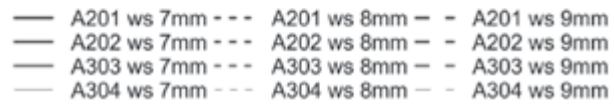

Figure 6. RI profiles calculated for different half window sizes: 7,8 and $9 \mathrm{~mm}$.

cone (A303), it can be noticed in Figure 7a) that the RI profile for A201 recognises the first layer boundary, whereas the RI profile for A303 does not; both RI profiles in Figure 7b) see the lens at a depth of $8.20 \mathrm{~m}$. In Figure 7c), the RI profile for A201 shows the presence of a layer boundary, whereas again the profile for A303 fails to identify it; finally, in Figure 7d) both RI profiles highlight the two boundaries and the lens. 


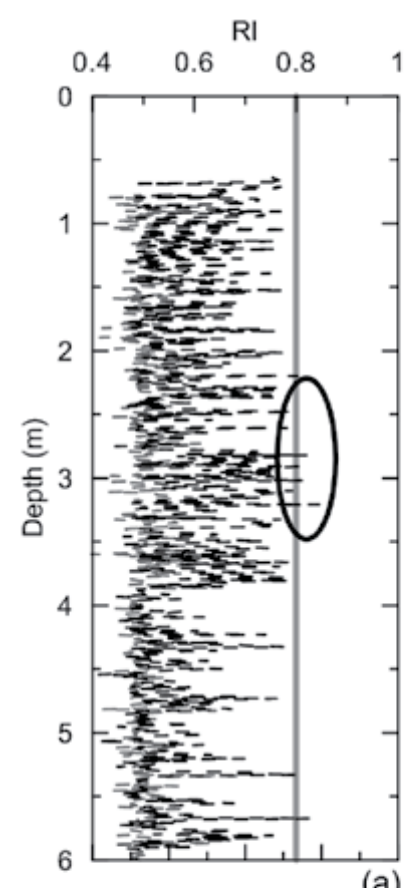

(a)

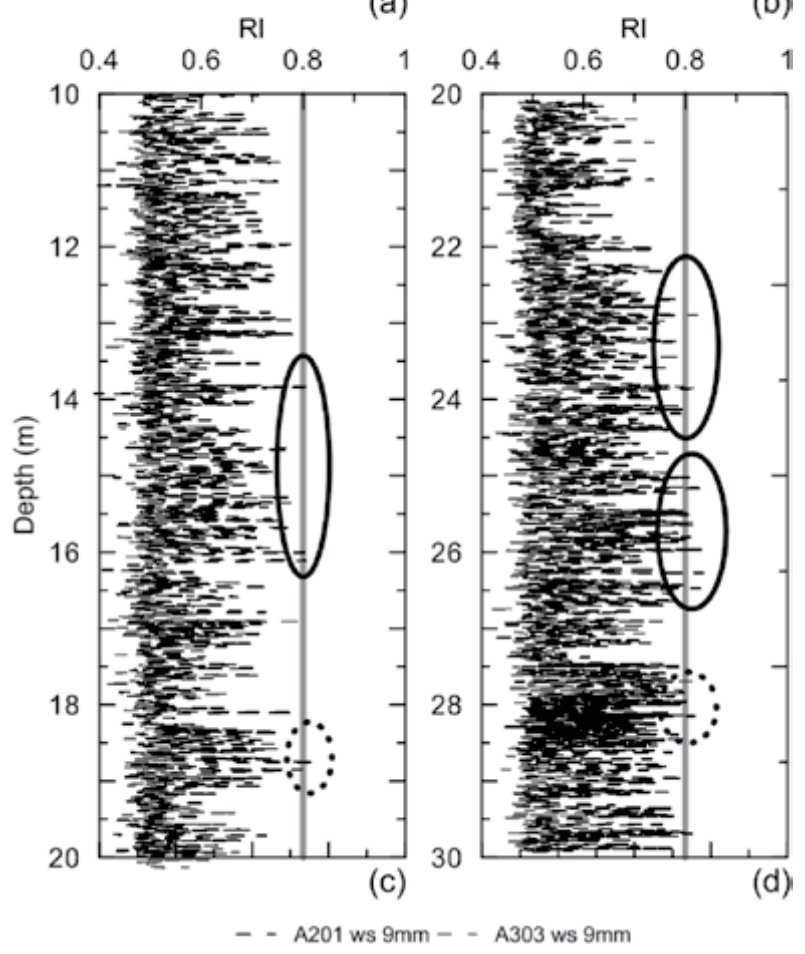

Figure 7. Comparison between RI profiles calculated for $\mathrm{Q}_{\mathrm{t}}$ readings from $10 \mathrm{~cm}^{2}$ (A201) and $5 \mathrm{~cm}^{2}$ (A303) cone dimensions.

Such results, confirmed by the other two RI profiles from A304 and A202, seem to be related to the mutual dimension of cones and lenses: the higher the lens thickness, the most effective the $10 \mathrm{~cm}^{2}$ cone. Hird \& Springman (2006) recommended the use of $5 \mathrm{~cm}^{2}$ cone when pore pressure $\mathrm{u}_{2}$ measurements from CPTUs are concerned. This can be due to the smaller dimension of the pore pressure filter in the $5 \mathrm{~cm}^{2}$ cone. Nonetheless, in this study, the combination of $\mathrm{q}_{\mathrm{c}}$ and $\mathrm{u}_{2}$ readings has been investigated by means of $\mathrm{Q}_{\mathrm{t}}$ profiles: this mean that when the tip bearing resistance is considered, the $10 \mathrm{~cm}^{2}$ cone is postulated to be more efficient.

The authors focus in the following sectoin on discussing the results from the A201 readings, because they are conservative with respect to the other CPTUs, but representative of the statistical features of the soils investigated.

\subsubsection{Trend function and spatial variability structure of the residuals}

According to the results of the preceding profiling activity, the de-trending step has been undertaken over the original $Q_{t}$ readings by means of the most likelihood rule. From such results, the $s_{u}$ trend functions for each layer have been derived by means of the following equation:

$s_{u}=\frac{Q_{t}}{N_{k t}} \cdot \sigma_{v 0}^{\prime}$

Figure 8 reports the trend functions calculated by this study on the A201 $s_{u}$ profile at the Wauwil

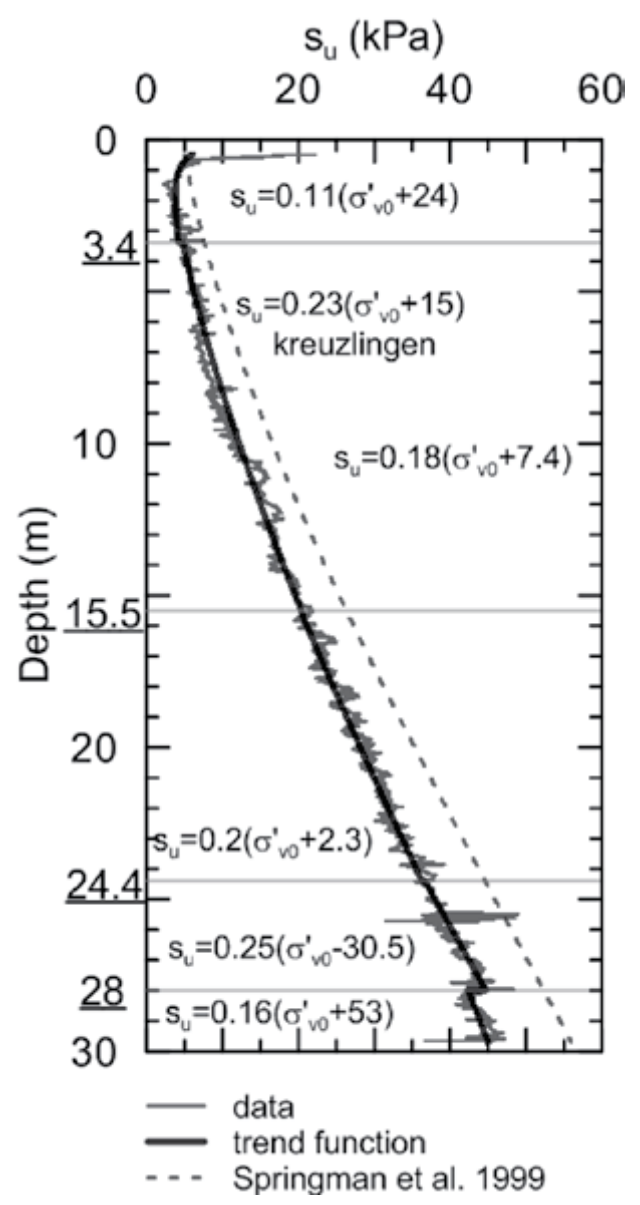

Figure 8. Comparison between $\mathrm{s}_{\mathrm{u}}$ trend functions calculated for the A201 CPTU by this study at Wauwil and at Kreuzlingen by Springman et al. (1999). 
site and the one derived from Springman et al. (1999) at Kreutzlingen.

It can be seen that Springman et al.'s prediction is not conservative at Wauwil, although a similar slope can be recognised. As far as the $s_{u}$ values at Wauwil are concerned, it can be seen that $s_{u}$ trends are similar for all layers, whereas the slope slightly changes from the top to the bottom: the $\mathrm{s}_{\mathrm{u}}$ trend increases over the depth up to $28 \mathrm{~m}$, where the slope decreases to about the second layer value. There is also a discontinuity at $28 \mathrm{~m}$, with a reduction in the $\mathrm{s}_{\mathrm{u}}$ value.

Based of this analysis, and taking into account the results from the other CPTU profiles, the authors suggest modifying the geotechnical profile in Figure 4 by inserting the lithological boundary at $28 \mathrm{~m}$, taking into account results from the statistical analysis.

Moreover, the statistical analysis allows the standard deviation and the scale of fluctuation associated with the trend functions to be calculated. Such quantities can be used within reliability based-design of shallow or deep foundations of transportation structures. The scale of fluctuation, compared with the foundation dimension, allows the amount of standard deviation to be reduced for designing purposes: the higher the scale of fluctuation, the higher the reduction in standard deviation. This means that estimations of soil property values are more reliable when they have a long scale of fluctuation.

In order to calculate such quantities correctly from residuals, the verification of residual stationarity in the weak sense is needed, in order to state that:

- standard deviation is constant along depth;

- the autocorrelation function only depends on the distance between observations.

At this end, the modified Bartlett method (Phoon et al. 2003) is used. Such a method is based on the classical Bartlett's test, which checks the equality of multiple sample variances for independent data sets. Taking two sample variances of two adjacent windows of $Q_{t}$ readings, called $s_{1}{ }^{2}$ and $\mathrm{s}_{2}{ }^{2}$, the test consists of comparing the Bartlett statistics $B_{\text {stat }}$ calculated for the data under analyses with the critical one, $B_{\text {crit }}$ :

$B_{\text {stat }}=\frac{2.30259(m-1)}{C}\left[2 \log s^{2}-\left(\log s_{1}^{2}+\log s_{2}^{2}\right)\right]$

where $m$ is the number of data points used to evaluate $\mathrm{s}_{1}^{2}$ or $\mathrm{s}_{2}^{2}, \mathrm{~s}^{2}$ is the pooled variance:

$s^{2}=\frac{s_{1}^{2}+s_{2}^{2}}{2}$

and $\mathrm{C}$ is a constant equal to $1+1 /(2(\mathrm{~m}-1))$.

A continuous Bartlett statistic profile can be easily generated by moving a sampling window over the simulated soil profile. In order to verify the stationarity of the residuals for each layer, the $\mathrm{B}_{\text {stat }}$ spiky profile must be lower than the $\mathrm{B}_{\text {crit }}$ reported here in Table 1, depending on four parameters:

1. the number of data points in one scale of fluctuation $\delta$ :

$$
k=\frac{\delta}{\Delta z}
$$

where $\Delta \mathrm{z}$ is the distance between two adjacent measures;

2. the normalised sampling length, $I_{1}$, which is the ratio between the total number of data points and $\mathrm{k}$ :

$$
I_{1}=\frac{n}{k}
$$

3. the normalised segment length, $\mathrm{I}_{2}$, which is the ratio between the number of data in a window $\mathrm{m}$ and $\mathrm{k}$ :

$$
I_{2}=\frac{m}{k}
$$

4. the autocorrelation fitting model. There are five models that can fit the empirical autocorrelation functions that are reported in Table 2. From each expression, the scale of fluctuation can be derived according to the relationships presented in the third column.

Whenever $\mathrm{B}_{\text {stat }}$ is less than $\mathrm{B}_{\text {crit }}$ at $5 \%$ level of significance, the stationarity condition for residuals is verified. The discussion on the best values for $\mathrm{k}, \mathrm{I}_{1}$ and $\mathrm{I}_{2}$ parameters is beyond the scope of this application, although it is presented in Phoon et al. (2003). Here, the values of $n, k, I_{1}$ and $I_{2}$ for the case studied are assumed to vary in the following value intervals:

$\mathrm{k} \in[5,50] ; \mathrm{n} \in[25,2500] ; \mathrm{I}_{1} \in[5,50]$ and $\mathrm{I}_{2}=1$

Table 1. Critical modified Bartlett test statistic at 5\% level of significance for five autocorrelation models.

Autocorrelation model Rejection criteria, $\mathrm{B}_{\text {crit }}$

Single exponential

Binary noise

Cosine exponential

Second-order Markov

Squared exponential
$(0.23 \mathrm{k}+0.71) \ln \left(\mathrm{I}_{1}\right)+0.91 \mathrm{k}+0.23$

$(0.30 \mathrm{k}+0.29) \ln \left(\mathrm{I}_{1}\right)+1.15 \mathrm{k}-0.52$

$(0.28 \mathrm{k}+0.43) \ln \left(\mathrm{I}_{1}\right)+1.291 \mathrm{k}-0.4$

$(0.423 \mathrm{k}-0.07) \ln \left(\mathrm{I}_{1}\right)+2.04 \mathrm{k}-3.32$

$(0.73 \mathrm{k}-0.98) \ln \left(\mathrm{I}_{1}\right)+2.35 \mathrm{k}-2.45$ 
Table 2. Autocorrelation function models.

\begin{tabular}{lll}
\hline $\begin{array}{l}\text { Autocorrelation } \\
\text { model }\end{array}$ & Expression & $\begin{array}{l}\text { Scale of } \\
\text { fluctuation }\end{array}$ \\
\hline $\begin{array}{l}\text { Single } \\
\text { exponential }\end{array}$ & $R(\tau)=\exp (-\lambda|\tau|)$ & $\delta=2 / \lambda$ \\
$\begin{array}{c}\text { Binary } \\
\text { noise }\end{array}$ & $R(\tau)=\left\{\begin{array}{cl}1-c|\tau||\tau| \leq 1 / c & \delta=2 / \lambda \\
0 & \\
\begin{array}{c}\text { Cosine } \\
\text { exponential }\end{array} & R(\tau)=\exp (-b|\tau|) \cos (\mathrm{b} \tau)\end{array}\right.$ \\
$\begin{array}{c}\text { Second-order } \\
\text { Markov }\end{array}$ & $R(\tau)=(1+\mathrm{d}|\tau|) \exp (-\mathrm{d}|\tau|)$ & $\delta=4 / d$ \\
$\begin{array}{c}\text { Squared } \\
\text { exponential }\end{array}$ & $R(\tau)=\exp \left[-(a \tau)^{2}\right]$ & $\delta=\sqrt{\pi} / a$ \\
\hline
\end{tabular}

Table 3 reports the $\mathrm{B}_{\text {crit }}$ values calculated for the case studied, which are used for checking the stationarity of residuals. Such critical values were not exceeded by all $\mathrm{B}_{\text {stat }}$ profiles calculated for the five layers for $\mathrm{Q}_{\mathrm{t}}$ profile from CPTU A201.

Finally, Table 4 summarises results of standard deviation and scale of fluctuation calculated for $s_{u}$ profiles. Such values are derived from $Q_{t}$ ones: the scale of fluctuation is the same for the two parameters, whereas the standard deviation has been calculated by means of the residuals calculated from the $s_{\mathrm{u}}$ profile and trend functions in Figure 8.

From Table 4, it can be noted that cosine exponential is the autocorrelation model for four out of five layers considered. The standard deviation is higher for the layers 4 and 5, which corresponds to the range of depth 24.4 to $31.0 \mathrm{~m}$, where lenses are interbedded in the strata. Such lenses are not taken into account in the statistical study.

The values of the scale of fluctuation decreases for the layers 3 to 5 . This result can be referred to the different depositional history of the five layers. Once again, the last two layers show a higher variability with respect to the shallower ones, as demonstrated by a very short scale of fluctuation. The scale of fluctuation represents the spatial length over which the values of the soil property investigated resemble each other. Thus, the first two layers up to $15.5 \mathrm{~m}$ show a similar standard deviation and their scales of fluctuation increase with the increase of the layer thickness. The third stratum maintains quite a low standard deviation, but its scale of fluctuation is much less. It seems to behave as a transitional layer from less variable to more highly variable conditions. Such results are confirmed by the statistical analyses of the other CPTUs, as shown in Figure 3.

From an engineering point of view, the first two strata, which are mostly relevant for superficial structures, show higher homogeneity of their mechanical properties thus, the values coming
Table 3. Bartlett parameter values for the case study (A201).

\begin{tabular}{lr}
\hline Layer depth $[\mathrm{m}]$ & $\mathrm{B}_{\text {crit }}$ \\
\hline $0.8 \div 3.4$ & $\mathbf{3 8}$ \\
$3.4 \div 15.5$ & $\mathbf{9 5}$ \\
$15.5 \div 24.4$ & $\mathbf{1 0 0}$ \\
$24.4 \div 28.0$ & $\mathbf{2 0}$ \\
$28.0 \div 30.0$ & $\mathbf{4 0}$ \\
\hline
\end{tabular}

Table 4. Statistics of $s_{u}$ spatial variability from CPTUs conducted at A201.

\begin{tabular}{llll}
\hline $\begin{array}{l}\text { Depth } \\
{[\mathrm{m}]}\end{array}$ & $\begin{array}{l}\text { Autocorrelation } \\
\text { fitting } \\
\text { model }\end{array}$ & $\begin{array}{l}\mathrm{s}_{\mathrm{u}} \\
\text { Standard } \\
\text { deviation }[\mathrm{kPa}]\end{array}$ & $\begin{array}{l}\text { Scale of } \\
\text { fluctuation } \\
{[\mathrm{m}]}\end{array}$ \\
\hline $\mathrm{A} 201$ & & 0.79 & 0.3 \\
\hline $0.8 \div 3.4$ & $\begin{array}{l}\text { Cosine } \\
\text { exponential }\end{array}$ & 0.9 \\
$3.4 \div 15.5$ & $\begin{array}{l}\text { Cosine } \\
\text { exponential }\end{array}$ \\
$15.5 \div 24.4$ & $\begin{array}{l}\text { Cosine } \\
\text { exponential } \\
\text { Binary noise } \\
24.4 \div 28.0\end{array}$ & 0.88 & 0.16 \\
$28.0 \div 31.0$ & $\begin{array}{l}\text { Cosine } \\
\text { exponential }\end{array}$ & 1.35 & 0.06 \\
\hline
\end{tabular}

from field investigations can be adopted with more confidence and lower margin of error.

\section{CONCLUDING REMARKS}

A statistical investigation at the Wauwil site has been developed in order to improve profile detection of layers in Swiss lacustrine clays from both spatial and mechanistic perspectives. Results from four CPTU readings in terms of undrained shear strength $s_{u}$ have been accomplished in terms of trend function, standard deviation and scale of fluctuation of $s_{u}$ along CPTUs over a depth of $30 \mathrm{~m}$. Accordingly, the following conclusions can be drawn:

1. up to $28 \mathrm{~m}, \mathrm{~s}_{\mathrm{u}}$ values increases with depth with an almost linear and continuous trend, as expected in a normally consolidated clay; at $28 \mathrm{~m}$ depth, a discontinuity in $\mathrm{s}_{\mathrm{u}}$ values has been deduced from the data.

2. A more variable $s_{u}$ statistical structure has been found starting from $15.5 \mathrm{~m}$. Such further results show that the deterministic profiling must be improved. Moreover, for design purposes, $s_{u}$ values below a depth of $15.5 \mathrm{~m}$ shall be taken with less confidence with respect to the values related to the shallower layers. 
Finally, a comparison between the efficiency of $10 \mathrm{~cm}^{2}$ and $5 \mathrm{~cm}^{2}$ cone readings, from a statistical standpoint, has been attempted. From previous studies, the $5 \mathrm{~cm}^{2}$ cone was recommended for detecting thin lens by virtue of their hydraulic properties. Results from RI profiles derived from $\mathrm{Q}_{\mathrm{t}}$ data, show that the $5 \mathrm{~cm}^{2}$ cone detects the lenses of a magnitude of a centimetre in thickness, but not always the layer interfaces, which are characterised by 10 times the lens thickness. This differentiation in outcome seems to be due to the relative dimension of the relative influences of the soil volume mobilised during the cone penetration with respect to the fabric of the soil and the lens/ boundary thickness and stiffness. Further study is needed to demonstrate conclusive evidence of this hypothesis.

\section{BIBLIOGRAPHY}

Cherubini C. \& Vessia G. 2006. Silt mixture CPT characterization for a reliability evaluation of pile total stress bearing capacity. Proc. of XIII Danube-European Conf. on Geotech. Eng., Ljubljana 2006.

Cherubini, C., Vessia, G. \& Pula W. 2007. Statistical soil characterization of Italian sites for reliability analyses. Proc. of 2 nd Intern. workshop on charact. \& eng. prop. of natural soils (Invited Paper), Singapore, 2007. Vol. 4: 2681-2706.

DeGroot D.J., \& Lutenegger A.J. 2003. Geology and engineering properties of Connecticut Valley varved clay. In T.S. Tan, K.K. Phoon, D.W. Hight, \& S. Leroueil (eds.), Proc. of the Conf. on Charact. and Eng. Prop. of Natural Soils, Singapore, 693-724. Rotterdam: Balkema.

Fenton, G.A. 1999. Random field modelling of CPT data. Journal of Geotech. and Geoenv.Eng., 125(6): 486-498.

Hai-Sui Yu 2004. James K. Mitchell Lecture. In situ soil testing: from mechanics to interpretation. In Viana da Fonseca \& Mayne (eds.), Proceedings ISC-2 on Geotechnical and Geophysical Site Characterization. Millpress: Rotterdam.

Heil, H.M., Huder, J. \& Amman, P. 1997. Determination of shear strength of soft lacustrine clays. Proc. 14th ICSMFE, Hamburg, 1997. (1): 507-510. Rotterdam: Balkema.

Hird, C.C. \& Springman, S.M. 2006. Comparative performance of $5 \mathrm{~cm}^{2}$ and $10 \mathrm{~cm}^{2}$ piezocones in a lacustrine clay. Géotechnique 56(6): 427-438.
Mayne, P.W., Coop, M.R., Springman, S.M., Huang, A. \& Zornberg, J.G. 2009. Geomaterials behavior and testing. Proc. 17th Int. Conf. On Soil Mechanics \& Geotechnical Engrg, Alexandria, Vol. 4: 2777-2872. Millpress-IOS Press: Rotterdam.

Matzinger, C. 2006. Wauwiler Seebodenlehm: Charakterisierung in geotechnischer Hinsicht. Diplomarbeit, Institut für Geotechnik, ETH Zürich.

Messerklinger, S. 2006. Non-linearity and small strain behaviour in lacustrine clay. Dissertation, No. 16512, ETH Zurich (available online at: http://e-collection. ethbib.ethz.ch).

Phoon, K.K., Quek, S.T. \& An, P. 2003. Identification of statistically homogeneous soil layers using modified Bartlett statistics. Journal of Geot. and Geoenv Eng. 129(7): 649-659.

Rey, R. 1994. Geotechnische Folgen der glazialen Vorbelastung von Seebodenablagerungen. PhD thesis Nr. 10631. ETH-Zurich, Switzerland.

Robertson, P.K. \& Campanella, R.G. 1988. Guidelines for Geotechnical Design Using CPT and CPTU. University of British Columbia, Vancouver, Department of Civil Engineering, Soil Mechanics Series 120.

Soccodato, F.M. 2003. Geotechnical properties of Fucino clayey soil. Characterisation and engineering properties of natural soils. In T.S. Tan, K.K. Phoon, D.W. Hight, \& S. Leroueil. Balkema (eds.), Proc. of the Conf. on Charact. and Eng. Prop. of Natural Soils, Vol. 1: 791-808, Singapore.

Springman, S.M., Trausch Giudici, J., Heil, H.M. \& Heim, R. 1999. Strength of Swiss Lacustrine Clay: Cone Penetration and Triaxial Test Data. Journal of the Transp. Res. Board, Transportation Research Record No. 1675: 1-9.

Trausch Giudici, J. 2004. Stress-strain characteristics of Seebodenlehm. Dissertation, No. 15528, ETH Zürich. (available online at: http://e-collection.ethbib.ethz.ch.)

Uzielli, M. \& Mayne, P.W. 2008. Comparative CPT-based classification of Cooper Marl, Proc. 3rd Int. Conf. on Site Charact., (ISC-3), Taipei (Taiwan) 2008. Taylor \& Francis Group: London.

Uzielli, M., Vannucchi, G. \& Phoon, K.-K. 2005. Random field characterisation of stress-normalized CPT parameters. Géotechnique, 55(1): 3-20.

VanMarcke, E. 1983. Random Fields: Analysis and Synthesis, MIT Press: Cambridge MA.

Wickremesinghe, D.S. \& Campanella, R.G. 1991. Statistical Methods of Soil Layer Boundary Location Using the Cone Penetration Test. Proc. 6th Int. Conf. on Applic. of Stat. and Prob. in Civil Eng., CERRAICASP6, 636-644. 